\title{
Short-range structure and thermal properties of barium tellurite glasses
}

Amarjot Kaur, Atul Khanna, and Fernando Gonzàlez

Citation: AIP Conference Proceedings 1832, 070015 (2017); doi: 10.1063/1.4980450

View online: http://dx.doi.org/10.1063/1.4980450

View Table of Contents: http://aip.scitation.org/toc/apc/1832/1

Published by the American Institute of Physics 


\title{
Short-Range Structure and Thermal Properties of Barium Tellurite Glasses
}

\author{
Amarjot Kaur $^{1}$, Atul Khanna ${ }^{1 *}$, Fernando Gonzàlez ${ }^{2}$ \\ ${ }^{1}$ Sensors and Glass Physics Laboratory, Department of Physics, Guru Nanak Dev University, Amritsar-143005, \\ Punjab, India \\ ${ }^{2}$ Department of Chemistry and Process \& Recourse Engineering, University of Cantabria, Santander-39005, Spain \\ *E-mail: atul.phy@gndu.ac.in
}

\begin{abstract}
BaO}-\mathrm{TeO}_{2}$ glasses containing 10 to $20 \mathrm{BaO}$ mol\% were prepared and characterized by X-ray diffraction, density measurements, differential scanning calorimetry and Raman spectroscopy. Glass density decreases with increase in $\mathrm{BaO}$ concentration from 10 to $20 \mathrm{~mol} \%$, due to replacement of heavier $\mathrm{TeO}_{2}$ by lighter $\mathrm{BaO}$, however glass transition temperature $\left(\mathrm{T}_{\mathrm{g}}\right)$ increases significantly from a value of $318^{\circ} \mathrm{C}$ to $327^{\circ} \mathrm{C}$ due to increase in average single bond enthalpy of the tellurite network. Raman studies found that glass short-range structure consists of $\mathrm{TeO}_{4}$ and $\mathrm{TeO}_{3}$ structural units and $\mathrm{BaO}$ modifies the network by producing the structural transformation: $\mathrm{TeO}_{4} \rightarrow \mathrm{TeO}_{3}$.
\end{abstract}

Keywords: Tellurite glasses, Thermal Properties, Raman studies. PACS: 64.70.kj, 65.60.+a, 33.20.Fb.

\section{INTRODUCTION}

Tellurite glasses are considered as good candidates for efficient photonic, memory switching devices and gas sensing devices due to their a wide optical transmission windows, extraordinary nonlinear-optical properties, relatively low phonon energies, lack of toxicity, good durability and glass stability. The structural variability of tellurite glasses can be used to tailor the their thermal, optical and chemical durability parameters [1].This possibility has generated lot of interest in structural investigations of tellurite glasses. $\mathrm{TeO}_{2}$ is a conditional glass former which requires very high quenching rates $10^{5}$ to $10^{6} \mathrm{~K} \mathrm{~s}^{-1}$ to form glass and modifiers such as metal oxides are added to enhance its glass forming ability and produce glasses at lower quenching rates of $\sim 10^{2} \mathrm{~K} \mathrm{~s}^{-1}[1,2]$. The basic structural units of tellurite glasses are $\mathrm{TeO}_{4}$ trigonal bipyramids (tbp) and $\mathrm{TeO}_{3}$ trigonal pyramid (tp). The addition of modifier $\mathrm{BaO}$ to the tellurite glasses breaks the random network and produces non-bridging oxygens (NBO) and substantial change in the glass network structure [3]. Barium tellurite glasses have ability to form a zero stress-optic and negative stress-optic response glasses [4]. $\mathrm{Er}^{3+}$-doped barium tellurite glass with high upconversion and near-infrared (NIR) luminescence efficiency show great potential for infrared concentrator and NIR sensor and is also, a promising candidate for energetic mid IR lasers [5]. The present work is devoted to the synthesis and characterization of glasses from the system: $(\mathrm{BaO})_{\mathrm{x}}\left(\mathrm{TeO}_{2}\right)_{(100-\mathrm{x})}$.

\section{EXPERIMENTAL}

The binary $(\mathrm{BaO})_{\mathbf{x}}\left(\mathrm{TeO}_{2}\right)_{(100-\mathrm{x})}$ tellurite glasses with $\mathrm{x}=10,15,20 \mathrm{~mol} \%$ were prepared. The Analytical Reagent grade chemicals of $\mathrm{TeO}_{2}$ (Aldrich, India $99 \%)$ and $\mathrm{BaCO}_{3}(\mathrm{CDH}$, India 99.9\%) were used as starting materials. The chemicals were mixed and ground in an agate mortar pestle for about $30 \mathrm{~min}$ and then transferred to a platinum crucible. A homogeneous mixture of chemicals was melted in an electric furnace at $850^{\circ} \mathrm{C}$ for $20 \mathrm{~min}$. Each glass sample was prepared by normal quenching in which the melt was poured on a brass block and a button shaped sample was prepared and immediately transferred to another furnace where it was annealed at $320^{\circ} \mathrm{C}$ for 30 min to avoid cracking by relieving internal stresses generated by quenching.

All samples were clear and transparent and characterized by X-ray diffraction (XRD), Differential Scanning Calorimetry (DSC) and Raman Spectroscopy. The glassy state of samples was confirmed by XRD studies on Bruker D8 Focus X-ray diffractometer with $\mathrm{Cu} \mathrm{K} \mathrm{K}_{\alpha}$ radiation $(\lambda=1.54056 \AA)$ in 
$2 \theta$ range of $10^{\circ}-70^{\circ}$. Density of glasses was measured by Archimedes method on an electronic balance of sensitivity $10^{-4} \mathrm{~g}$ using dibutylpthalate (DBP) as an immersion fluid. DSC studies were performed on a SETARAM SETYS 16 TG-DSC system in temperature range of $200-800^{\circ} \mathrm{C}$ at heating rate of $10^{\circ} \mathrm{Cmin}^{-1}$. Raman studies were performed on Renishaw inVia Reflex Micro-Raman Spectrometer having $514.5 \mathrm{~nm}$ Argon Laser (50 mW), 2400 line $/ \mathrm{mm}$ diffraction grating and an edge filter for recording the Stokes spectra and a Peltier cooled CCD detector.

\section{RESULTS AND DISCUSSION}

\subsection{Structure}

Figure 1 shows the XRD patterns of three barium tellurite glasses, all samples exhibit broad halos centered at $2 \theta \sim 27^{\circ}$ and $50^{\circ}$ due to the short-range order in the samples.

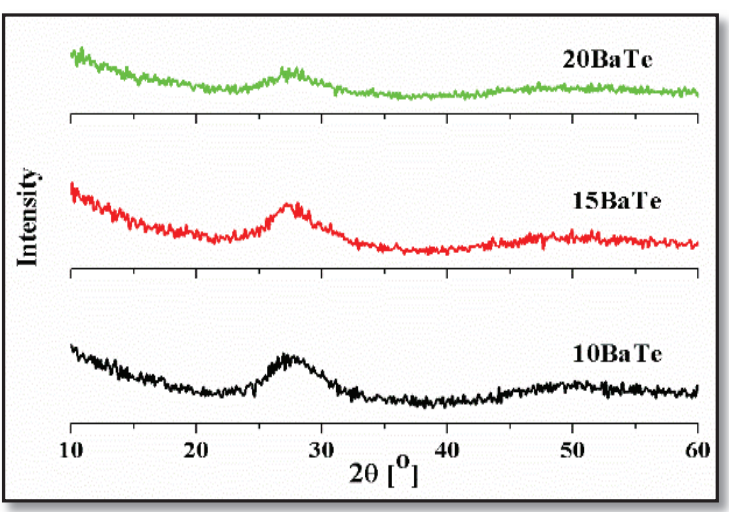

FIGURE 1. XRD patterns of $\mathrm{BaO}-\mathrm{TeO}_{2}$ glasses.

\subsection{Density measurements:}

It can be seen from Table 1 and Figure 2 that as the concentration of $\mathrm{BaO}$ increases from 10 to $20 \mathrm{~mol} \%$, density, $\mathrm{d}$ decreases from 5.58 to $5.52 \mathrm{~g} \mathrm{~cm}^{-3}$ while the molar volume, $\mathrm{V}_{\mathrm{M}}$ increases slightly from 28.48 to $28.68 \mathrm{~cm}^{3} \mathrm{~mol}^{-1}$.

the values are given in Table 1. Figure 3 shows that $T_{g}$ increases with $\mathrm{BaO}$ molar concentration (glass modifier). Glass transition temperature characterizes the strength of the glass network. The parameter $\Delta \mathrm{T}=\mathrm{T}_{\mathrm{c}}-\mathrm{T}_{\mathrm{g}}$ is commonly used to evaluate the glass stability against crystallization. The value of $\Delta \mathrm{T}$ decreases from $143^{\circ} \mathrm{C}$ to $102^{\circ} \mathrm{C}$ on increasing $\mathrm{BaO}$ concentration. Hence, the thermal stability of glasses against devitrification decreases.

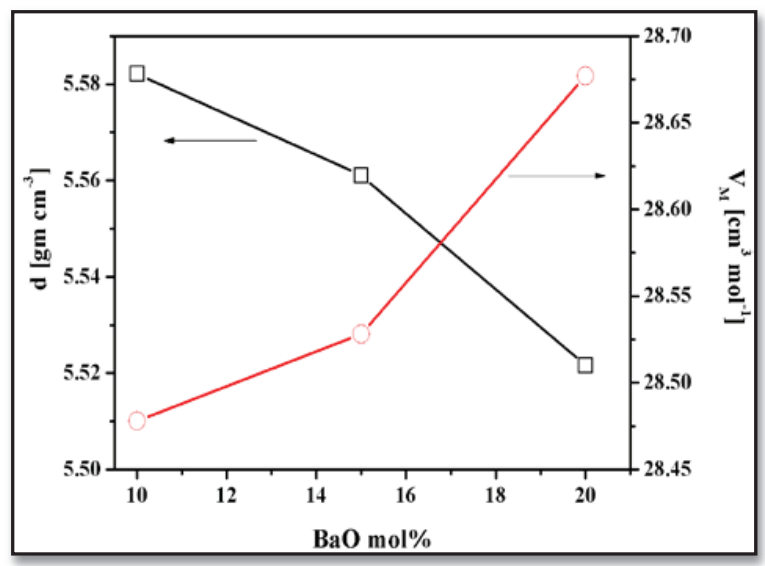

FIGURE 2. Variation of density and molar volume in $\mathrm{BaO}-$ $\mathrm{TeO}_{2}$ glasses with $\mathrm{BaO}$ mol\%.

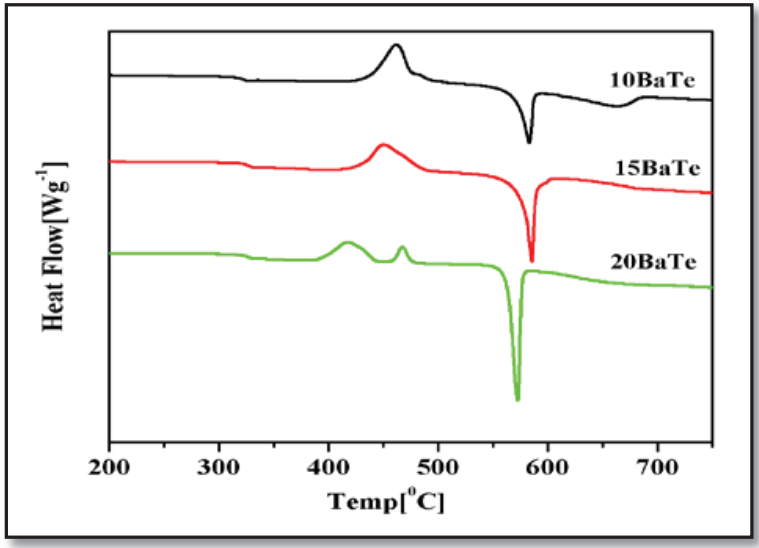

FIGURE 3. DSC patterns of $\mathrm{BaO}_{-} \mathrm{TeO}_{2}$ glasses.

TABLE 1. Density, molar volume, $\mathrm{N}_{\mathrm{Te}-\mathrm{O}}$ and DSC data for barium tellurite glasses.

\begin{tabular}{|c|c|c|c|c|c|c|c|c|c|c|}
\hline \multirow[t]{2}{*}{$\begin{array}{l}\text { Sample } \\
\text { Code }\end{array}$} & \multicolumn{2}{|c|}{$\begin{array}{c}\text { Composition } \\
\text { mol. } \%\end{array}$} & \multirow[t]{2}{*}{$\begin{array}{l}\text { Density (d) } \\
\left(\mathrm{g} \mathrm{cm}^{-3}\right)\end{array}$} & \multirow{2}{*}{$\begin{array}{c}\text { Molar } \\
\text { Volume }\left(\mathrm{V}_{\mathrm{M}}\right) \\
\left(\mathrm{cm}^{3} \mathrm{~mol}^{-1}\right) \\
\end{array}$} & \multirow[t]{2}{*}{$\begin{array}{c}T_{g} \\
\left({ }^{\circ} \mathbf{C}\right)\end{array}$} & \multicolumn{2}{|l|}{$\mathbf{T}_{\mathrm{c}}$} & \multicolumn{2}{|c|}{$\begin{array}{l}\mathrm{T}_{\mathrm{m}} \\
\left({ }^{\circ} \mathrm{C}\right)\end{array}$} & \multirow[t]{2}{*}{$\mathbf{N}_{\text {Te-O }}$} \\
\hline & $\mathrm{BaO}$ & $\mathrm{TeO}_{2}$ & & & & $T_{c 1}$ & $T_{c 2}$ & $T_{\mathrm{m} 1}$ & $\mathbf{T}_{\mathrm{m} 2}$ & \\
\hline 10BaTe & 10 & 90 & 5.58 & 28.48 & 318 & 461 & - & 582 & 662 & 3.54 \\
\hline $15 \mathrm{BaTe}$ & 15 & 85 & 5.56 & 28.53 & 325 & 450 & - & 585 & - & 3.42 \\
\hline 20BaTe & 20 & 80 & 5.52 & 28.68 & 327 & 435 & 488 & 600 & - & 3.43 \\
\hline
\end{tabular}

\subsection{DSC Results:}

The thermal characteristics i.e. the glass transition temperature $\left(\mathrm{T}_{\mathrm{g}}\right)$, crystallization temperature $\left(\mathrm{T}_{\mathrm{c}}\right)$ and liquidus temperature $\left(\mathrm{T}_{\mathrm{m}}\right)$ were measured by DSC and

\subsection{Raman Study:}

Figure 4 is the Raman spectra of three glasses which contains two broad bands in the ranges: $375-550 \mathrm{~cm}^{-1}$ (bending vibration of Te-O-Te linkages) and 550-840 
$\mathrm{cm}^{-1}$ (stretching vibrations of $\mathrm{TeO}_{4}$ tbp and $\mathrm{TeO}_{3}$ tp structural units). The band at $\sim 54 \mathrm{~cm}^{-1}$ is the boson peak, which is a universal feature of glassy phase. The Raman spectra were baseline corrected and deconvoluted with peaks centered at $609,662,719,778$ $\mathrm{cm}^{-1}$ (Figure 5). The co-ordination number of Te ions with oxygens was calculated from the area ratios of the deconvoluted bands [6]:

$$
N_{T e-O}=3+\frac{A_{609}+A_{662}}{A_{719}+A_{778}+A_{609}+A_{662}}
$$

The Te-O coordination number decreases from a value of 3.54 to 3.43 with increase in $\mathrm{BaO}$ concentration from 10 to $20 \mathrm{~mol} \%$.

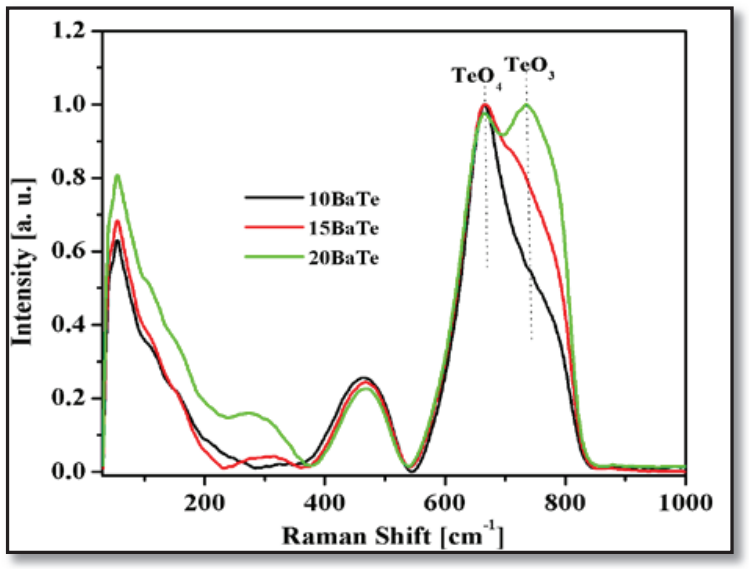

FIGURE 4. Raman spectra of $\mathrm{BaO}-\mathrm{TeO}_{2}$ glasses.

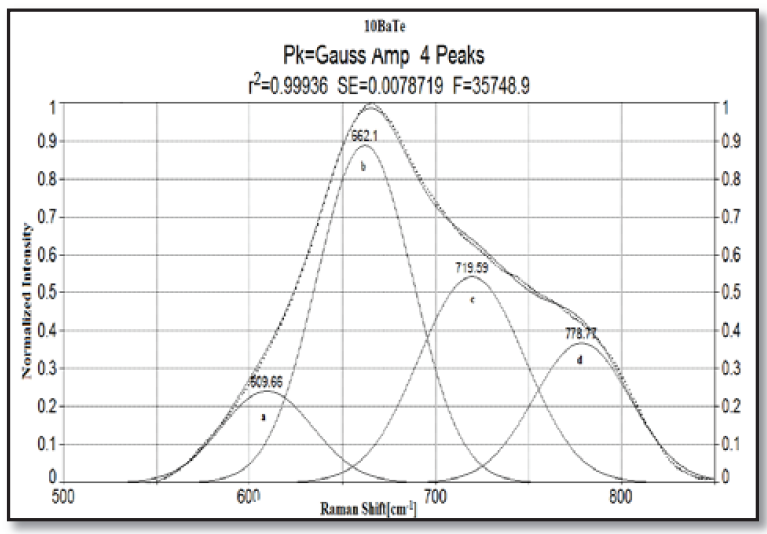

FIGURE 5. Deconvoluted Raman spectra of 10-mol.\% $\mathrm{BaO}$ of Barium Tellurite glass.

\section{CONCLUSIONS}

Barium tellurite glasses were prepared and characterized by XRD, density, DSC and Raman studies. Glass density correlates directly with molecular mass of the constituents while $\mathrm{T}_{\mathrm{g}}$ is a direct function of average single bond enthalpy of the network. Since the enthalpy of Ba-O bonds $\left(562 \mathrm{~kJ} \mathrm{~mol}^{-1}\right)$ is significantly higher than that of $\mathrm{Te}-\mathrm{O}$ bonds $\left(376 \mathrm{~kJ} \mathrm{~mol}^{-1}\right), \mathrm{Tg}$ increases with $\mathrm{BaO}$ concentration. The Raman spectra of the glasses were interpreted in terms of the structural transformations produced by $\mathrm{BaO}$. Increasing content of $\mathrm{BaO}$ accelerates the conversion of $\mathrm{TeO}_{4}$ and $\mathrm{TeO}_{3+1}$ into $\mathrm{TeO}_{3}$ units having non-bridging oxygens.

\section{REFERENCES}

1. R.A. El-Mallawany, Tellurite glasses handbook: physical properties and data. 2011: CRC press.

2. A. Kaur, A. Khanna, F. González, C. Pesquera and B. Chen, Journal of Non-Crystalline Solids 444, 110 (2016).

3. D. Dutta and A. Ghosh, The Journal of Chemical Physics 128, 044511 (2008).

4. $\quad$ M. Guignard and J.W. Zwanziger, Journal of NonCrystalline Solids 353, 1662-1664 (2007).

5. W. Wang, J. Yuan, L. Li, D. Chen, Q. Qian and Q. Zhang, Optical Materials Express 5, 2964-2977 (2015).

6. N. Kaur, A. Khanna, M. Gónzález-Barriuso, F. González and B. Chen, Journal of Non-Crystalline Solids 429, 153-163 (2015). 